Article

\title{
Doping of Chlorine from a Neoprene Adhesive Enhances Degradation Efficiency of Dyes by Structured $\mathrm{TiO}_{2}$-Coated Photocatalytic Fabrics
}

\author{
Zhen Cao ${ }^{1,+}$, Tingting Zhang ${ }^{1,+}$, Pin Ren ${ }^{1}$, Ding Cao ${ }^{1}{ }^{\mathbb{D}}$, Yanjun Lin ${ }^{1}$, Liren Wang ${ }^{1}$, \\ Bing Zhang ${ }^{2}$ and $\mathrm{Xu}$ Xiang ${ }^{1, * \mathbb{D}}$ \\ 1 State Key Laboratory of Chemical Resource Engineering, Beijing University of Chemical Technology, \\ Beijing 100029, China; xiangxubuct@163.com (Z.C.); zhangtt0729@163.com (T.Z.); renpin135@126.com (P.R.); \\ caoding@mail.buct.edu.cn (D.C.); linyj@mail.buct.edu.cn (Y.L.); wanglr@mail.buct.edu.cn (L.W.) \\ 2 School of Chemical Engineering, Zhengzhou University, 100 Science Avenue, Zhengzhou 450001, China; \\ zhangb@zzu.edu.cn \\ * Correspondence: xiangxu@mail.buct.edu.cn \\ $+\quad$ These authors contribute equally.
}

Received: 22 November 2019; Accepted: 31 December 2019; Published: 2 January 2020

\begin{abstract}
We demonstrate that using neoprene as a binder during the fabrication of $\mathrm{TiO}_{2}$-coated fabrics enhances the rates of photodegradation of dyes by the fabrics. The neoprene binder simultaneously modifies the surface of the $\mathrm{TiO}_{2}$ particles with $\mathrm{Cl}$ and dopes the $\mathrm{TiO}_{2}$ with $\mathrm{Cl}$, without requiring high temperatures or other harsh laboratory treatments. The adsorption of chlorine on the surface and doping of the lattice with chlorine were confirmed by X-ray photoelectron spectroscopy. The chloride ions adsorbed onto the $\mathrm{TiO}_{2}$ surface introduces a negative surface charge that enhances electrostatic adsorption of cationic dyes, and greatly improves the self-sensitizing degradation performance of the dyes. Chloride ions replace lattice oxygen atoms in $\mathrm{TiO}_{2}$, inducing lattice oxygen vacancies, that reduce the apparent band gap of the $\mathrm{TiO}_{2}$ particles, enhancing its absorption of visible light, and further increasing the photocatalytic activity of the composite-coated fabric. The degradation rates of RhB and MB over 50 min were $95.2 \%$ and $96.0 \%$, respectively. The degradation rate for MO reached $95.4 \%$ after $180 \mathrm{~min}$. We also show that $\bullet \mathrm{OH}$ and $\bullet \mathrm{O}^{2-}$ are active agents in the dye-degradation mechanism. Moreover, the photocatalytic performance of the composite-coated fabric was unchanged after eight cycles of photocatalytic degradation of RhB, demonstrating that the photocatalyst-coated fabrics was highly recyclable.
\end{abstract}

Keywords: $\mathrm{TiO}_{2}$-coated fabrics; self-sensitizing degradation; neoprene; chlorine doping; oxygen vacancies

\section{Introduction}

Continued industrial development has caused water pollution to become an increasingly serious problem. Organic dyes discharged during industrial activities, including textile production, printing, tanning, and papermaking, have damaged the environment and have even threatened human health [1]. Moreover, most organic dyes used in industries contain aromatic conjugated structures that are chemically stable and difficult to degrade [2]. Therefore, the development of effective methods for the removal of dyes from the industrial wastewater is important for environmental sustainability [3-5]. The main methods used to remove dyes from wastewater include adsorption, electrochemical oxidation, filtering, degradation by microbes [6], and photocatalytic degradation. Although adsorption is effective in removing dyes from water, adsorption does not eliminate contamination because the process does not convert the dye molecules to harmless chemicals. Photocatalytic degradation is a more recently developed method that uses sunlight to stimulate semiconducting catalysts to generate strongly 
oxidative free radicals that attack most organic substances in water. Photocatalytic degradation has low operating costs and is a promising energy-saving technology for wastewater treatment.

$\mathrm{TiO}_{2}$ is currently the photocatalyst that is most widely used for wastewater treatment; $\mathrm{TiO}_{2}$ is chemically stable, non-toxic, inexpensive, and exhibits high photocatalytic activity [7-10]. However, $\mathrm{TiO}_{2}$ has a wide band gap that limits its light absorption to ultraviolet wavelengths, and exhibits high rates of recombination for photogenerated electrons and holes. Furthermore, $\mathrm{TiO}_{2}$ has limited capacity for adsorption of pollutants, and small particles of $\mathrm{TiO}_{2}$ agglomerate easily [11-13]. In combination, these drawbacks limit the ability of $\mathrm{TiO}_{2}$ to use sunlight efficiently, and result in low photocatalytic efficiencies [14]. Therefore, increasing the photocatalytic activity of $\mathrm{TiO}_{2}$ requires the development of methods that either enhance the absorption spectrum of $\mathrm{TiO}_{2}$ or inhibit the recombination of photogenerated electron-hole pairs. Recently, a variety of methods have been used to increase the photocatalytic activity of $\mathrm{TiO}_{2}$, such as doping with non-metals or combining $\mathrm{TiO}_{2}$ with another semiconductor or with a photosensitizer. $\mathrm{TiO}_{2}$ has been doped with $\mathrm{N}, \mathrm{C}, \mathrm{F}, \mathrm{S}$, and I [15-19]; these dopants enhanced the photocatalytic activity by increasing the absorption spectrum of the $\mathrm{TiO}_{2}$. In recent years, efforts to extend the $\mathrm{TiO}_{2}$ absorption spectra into the visible range have focused on inducing the formation of $\mathrm{Ti}^{3+}$ defects. For example, $\mathrm{Ti}^{3+}$ defects can be induced by generating oxygen vacancies either through a reduction reaction that occurs under high pressures of $\mathrm{H}_{2}$ [20-22] or through vacuum activation $[23,24]$. However, these methods are expensive and require harsh conditions, and therefore are rarely suitable for practical applications.

Dye sensitization is a well-known and frequently used method of expanding the effective absorption spectra of $\mathrm{TiO}_{2}$-based materials to visible wavelengths. Absorption of light by dye molecules on the surface of $\mathrm{TiO}_{2}$ excites electrons in the dye that are then injected into the $\mathrm{TiO}_{2}$ conduction band. Over time, the dye molecules become self-sensitized and degraded. Modification of the $\mathrm{TiO}_{2}$ surface can enhance the adsorption of dyes and improve the photocatalytic performance; for example, Jincai Zhao et al. showed that the surface of $\mathrm{TiO}_{2}$ can be modified with $\mathrm{F}$ ions through $\mathrm{HF}$ etching [25]. Ji-Jun Zou et al. showed that the electronic structure of the titanium dioxide surface can be regulated by aqueous media [26] using a method that changes surface charge that can be held by the $\mathrm{TiO}_{2}$, and thereby enhancing the adsorption of cationic dyes. However, selective adsorption of dyes has not yet substantially enhanced the photocatalytic activity of $\mathrm{TiO}_{2}$, and modifications of $\mathrm{TiO}_{2}$ that can be performed under standard laboratory conditions for maximum compatibility with large-scale catalyst recovery from dye-contaminated wastewaters have not yet yielded significant improvements in photocatalytic activity.

Herein, a small amount of neoprene is used as an adhesive, which is an excellent polymer adhesive. It has stable physical and chemical properties, strong adhesion, aging resistance, heat resistance, and excellent chemical resistance [27]. It is widely used in many fields such as wires and cables, tapes, adhesives etc. [28]. The crosslinking ability of neoprene when heated has been reported. Metal oxide e.g., $\mathrm{ZnO}$ can be used as an agent for the crosslinking reaction of neoprene. In the crosslinking process, the $\mathrm{C}=\mathrm{C}$ double bond on the polarity of chlorine can react with a crosslinking agent $\mathrm{ZnO}$. The chlorine replaces the lattice oxygen of $\mathrm{ZnO}$ [29].

We describe a one-step method for modifying the $\mathrm{TiO}_{2}$ surface and doping the $\mathrm{TiO}_{2}$ with $\mathrm{Cl}$. In this method, P25 nanoparticles are affixed to fabric using a neoprene (chloroprene) binder. The preparation modifies the $\mathrm{TiO}_{2}$ surface and dopes the lattice with $\mathrm{Cl}$ without requiring high-temperature calcination or other subsequent treatments. Chloride ions adsorbed to the surface enhance electrostatic adsorption of cationic dyes, improving the self-sensitized degradation of the dye, while chloride ions in the lattice replace oxygen leaving oxygen vacancies that enhance the absorption of visible light by the $\mathrm{TiO}_{2}$. The photocatalyst can be recycled and stabilized while on the surface of the fabric. The method is simple, low-cost, compatible with mass production, and applicable to treatment of wastewaters from printing and dyeing industries. 


\section{Results}

Figure 1 compares the SEM micrographs of samples of pure and photocatalyst-coated fabrics. The surface of the pure fabric was smooth, and silky fibers were clearly visible; the surface of the photocatalyst-coated fabric was rough, and $\mathrm{TiO}_{2}$ particles were clearly uniformly dispersed on, and closely adhered to, fabric fibers. Thus, the simple spraying method yielded a photocatalyst-coated fabric. Figure 2 compares transmission-electron micrographs of $\mathrm{Cl}-\mathrm{TiO}_{2}$ and $\mathrm{P} 25$ at low and high resolutions. $\mathrm{Cl}-\mathrm{TiO}_{2}$ was more readily dispersed than $\mathrm{P} 25$, and the particle size of $\mathrm{Cl}_{-}-\mathrm{TiO}_{2}$ was slightly smaller than that of $\mathrm{P} 25$. We hypothesize that the $\mathrm{C}-\mathrm{TiO}_{2}$ is more readily dispersed than $\mathrm{P} 25$ because the $\mathrm{Cl}$ ions on the surface of $\mathrm{Cl}-\mathrm{TiO}_{2}$ replace the hydroxyl group on the surface, reducing the degree of agglomeration of $\mathrm{TiO}_{2}$. The lattice fringes of $\mathrm{Cl}-\mathrm{TiO}_{2}$ and $\mathrm{P} 25$ were clearly visible in the high-resolution TEM images. An interplanar spacing of $0.353 \mathrm{~nm}$ was measured and is attributable to the (101) crystal plane of the anatase crystal form of $\mathrm{TiO}_{2}$ (JCPDS 21-1272). HRTEM images confirmed the presence of defective structures in $\mathrm{Cl}_{-} \mathrm{TiO}_{2}$, most likely because of doping of the $\mathrm{TiO}_{2}$ by chloride ions. The EDS mapping of $\mathrm{Cl}_{-}-\mathrm{TiO}_{2}$ is shown in Figure 2e. The results showed that $\mathrm{Ti}, \mathrm{O}$, and $\mathrm{Cl}$ elements was uniformly dispersed in the catalyst, confirming the presence of chlorine in $\mathrm{Cl}-\mathrm{TiO}_{2}$.

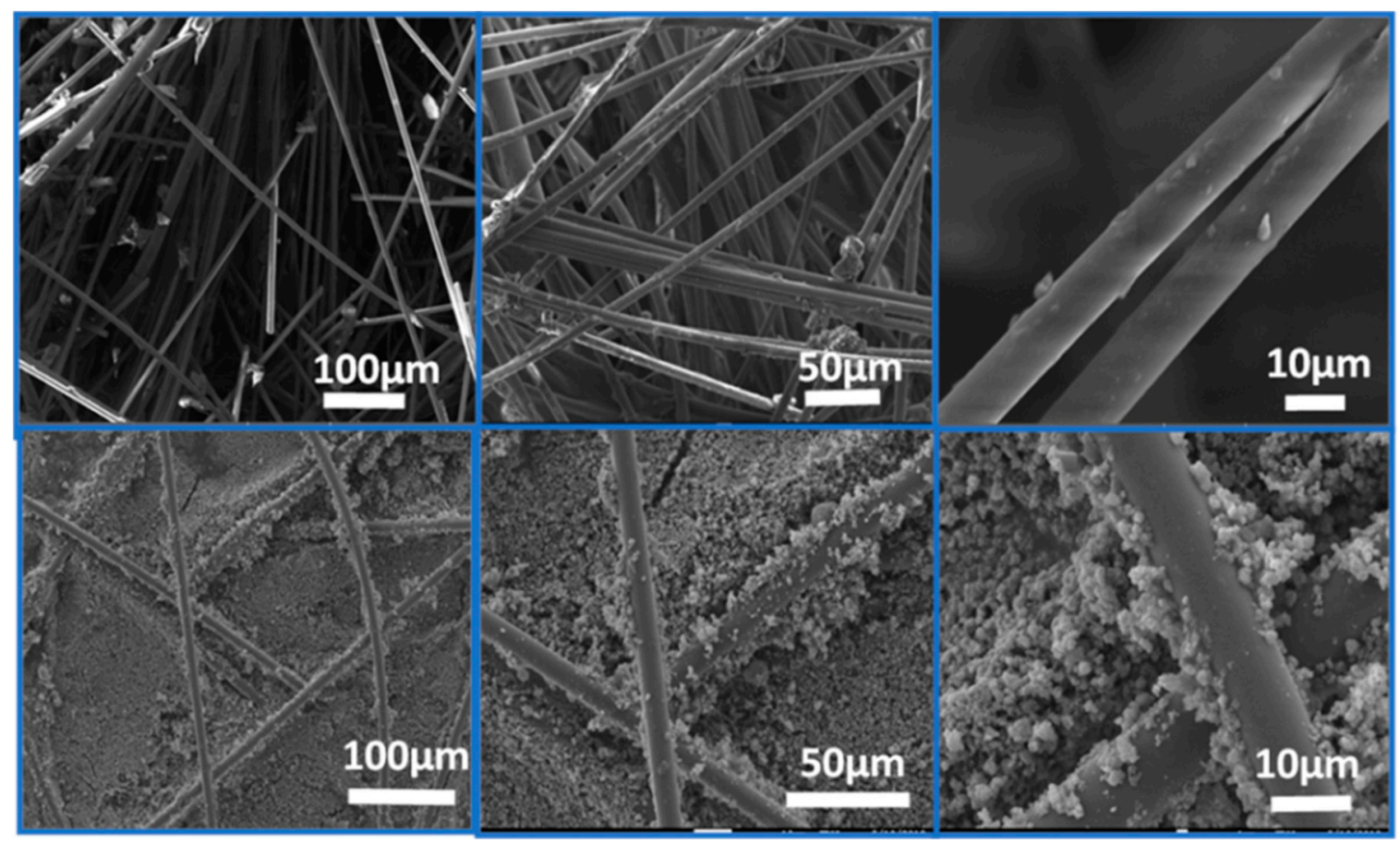

Figure 1. Scanning-electron micrographs of pure fabrics (top row) and photocatalyst-coated fabrics (bottom row).

Figure 3 shows $X$-ray diffraction patterns obtained for composite-coated and control samples and for $\mathrm{P} 25$ and $\mathrm{Cl}-\mathrm{TiO}_{2}$. The untreated pure fabric exhibited diffraction peaks at $18.0^{\circ}$ and $25.8^{\circ}$. These peaks remained present in the spectra after coating the fabric with both neoprene and $\mathrm{TiO}_{2}$, indicating that the fabric was not damaged. The fabric peak was relatively weaker for composite-coated fabrics because the fabric surface was covered by neoprene and $\mathrm{TiO}_{2}$ coatings. In addition, the photocatalyst-coated fabric exhibited additional peaks at $25.3^{\circ}, 27.3^{\circ}, 37.8^{\circ}, 48.0^{\circ}, 53.9^{\circ}, 55.1^{\circ}, 62.7^{\circ}$, corresponding to that of P25 [30]. The XRD data further support that $\mathrm{TiO}_{2}$ (P25) successfully dispersed onto the fabric surface, consistent with the SEM observations. Moreover, the XRD pattern for the $\mathrm{Cl}-\mathrm{TiO}_{2}$ obtained by pulverizing and filtering the coated fabric was consistent with the crystal form of P25, indicating that doping $\mathrm{TiO}_{2}$ with chloride did not affect the crystal structure. 


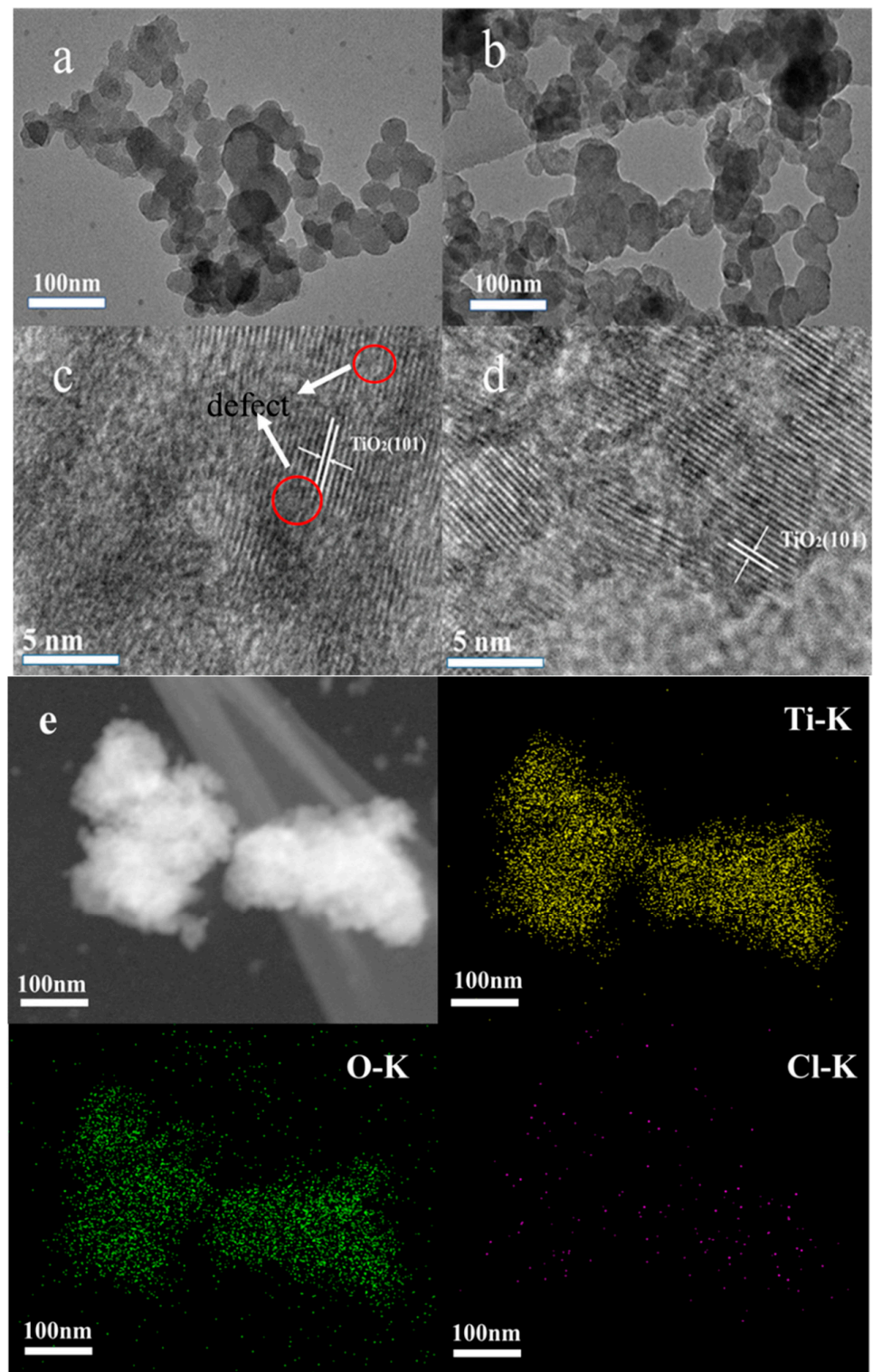

Figure 2. Low-resolution and high-resolution transmission-electron micrographs of $(\mathbf{a}, \mathbf{c}) \mathrm{Cl}_{-} \mathrm{TiO}_{2}$ and (b,d) P25. (e) Energy-dispersive X-ray spectrum EDX maps of $\mathrm{Ti}, \mathrm{O}$, and $\mathrm{Cl}$ in $\mathrm{Cl}-\mathrm{TiO}_{2}$.
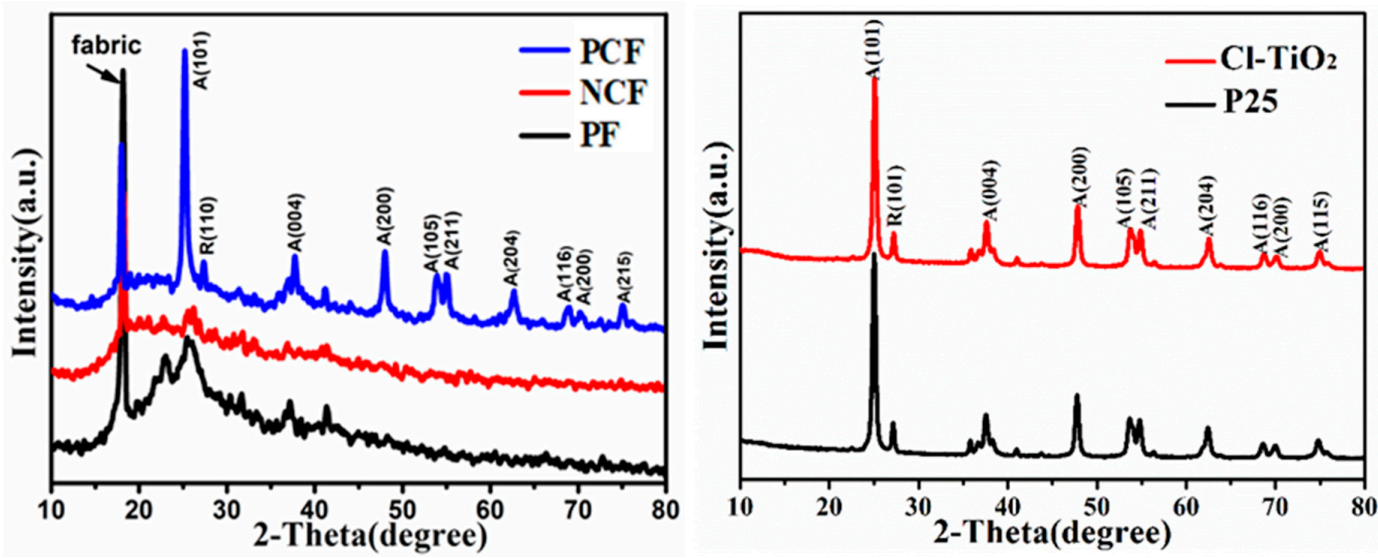

Figure 3. XRD patterns of pure fabric, neoprene-coated fabric, and photocatalyst-coated fabric (in the left). XRD patterns of $\mathrm{P} 25$ and $\mathrm{Cl}-\mathrm{TiO}_{2}$ (in the right). 
Figure 4 shows the zeta potentials of suspensions of $\mathrm{TiO}_{2}$ and $\mathrm{Cl}-\mathrm{TiO}_{2}$ at different $\mathrm{pHs}$. The $\mathrm{TiO}_{2}$ suspension is amphoteric due to the presence of surface hydroxyl groups that undergo the following acid-base equilibration [31,32]:

$$
\begin{aligned}
\mathrm{TiOH}^{2+} & \leftrightarrow \mathrm{TiOH}+\mathrm{H}^{+} \\
\mathrm{TiOH} & \leftrightarrow \mathrm{TiO}^{-}+\mathrm{H}^{+}
\end{aligned}
$$

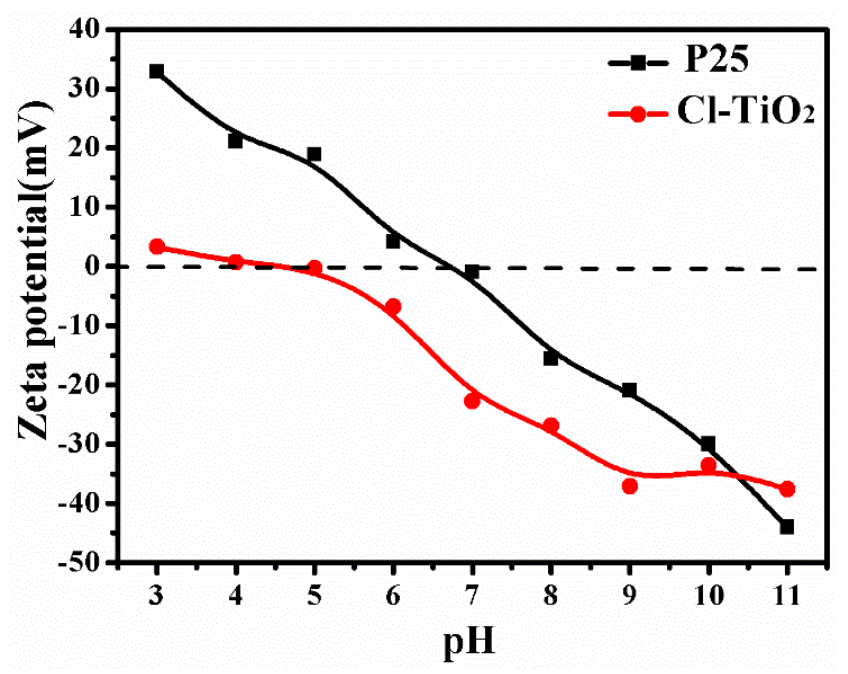

Figure 4. Zeta potentials of $\mathrm{P} 25$ and $\mathrm{Cl}-\mathrm{TiO}_{2}$.

As shown in the Figure 4, the isoelectric point of the $\mathrm{TiO}_{2}$ particles is at $\mathrm{pH}=6.7$. In an acidic environment with $\mathrm{pH}<\mathrm{pH}_{\mathrm{zpc}}$, the zeta value of $\mathrm{TiO}_{2}$ is determined by the adsorption of hydrogen ions on the surface hydroxyl groups to form $\mathrm{TiOH}^{2+}$. Similarly, in an alkaline environment with $\mathrm{pH}>\mathrm{pH}_{\mathrm{zpc}}$, the hydroxyl groups on the surface of $\mathrm{TiO}_{2}$ are deprotonated and form a $\mathrm{TiO}^{-}$structure with a negative zeta value. However, the zeta value of the $\mathrm{Cl}-\mathrm{TiO}_{2}$ suspension was negative in the range of $\mathrm{pH} 5-11$, indicating that the adsorption of chloride ions on the surface of $\mathrm{TiO}_{2}$, promotes a negative surface charge on the $\mathrm{TiO}_{2}$. The negative surface charge is beneficial for the selective adsorption of cationic dyes in the photocatalytic reaction process, and improves the degradation performance of the $\mathrm{TiO}_{2}$ for cationic dyes.

Figure 5 compares the UV-Vis absorption spectra for the composite-coated and control samples. The pure fabric and the chloroprene-coated fabric had weak absorption intensities across the $200 \mathrm{~nm}-800$ $\mathrm{nm}$ wavelength range, indicating that neoprene does not substantially enhance light absorption by the fabric. The fabric coated with P25 exhibited a high absorption value in the ultraviolet region, and weak absorption in the visible light region, consistent with the absorption of $\mathrm{TiO}_{2}(\mathrm{P} 25)$. The absorption intensity of the photocatalyst-coated fabric was enhanced in the visible region across the $400 \mathrm{~nm}-800$ $\mathrm{nm}$ wavelength range, possibly because of chloride-ion doping of the $\mathrm{TiO}_{2}$ by the neoprene rubber. The absorption of chlorine-doped $\mathrm{TiO}_{2}$ is red shifted relative to $\mathrm{P} 25$, because the chlorine doping reduces the apparent band gap of titanium dioxide [33]. The band gaps of $\mathrm{P} 25$ and $\mathrm{Cl}-\mathrm{TiO}_{2}$ were estimated to be $2.94 \mathrm{eV}$ and $2.53 \mathrm{eV}$, respectively, based on the analyses of diffuse reflectance spectra using the relationship between band gap and (ahv)1/2 for indirect-transition semiconductors. The narrower band gap of $\mathrm{Cl}-\mathrm{TiO}_{2}$ is beneficial for the absorption of light, and significantly enhances the photocatalytic performance relative to $\mathrm{P} 25$. 

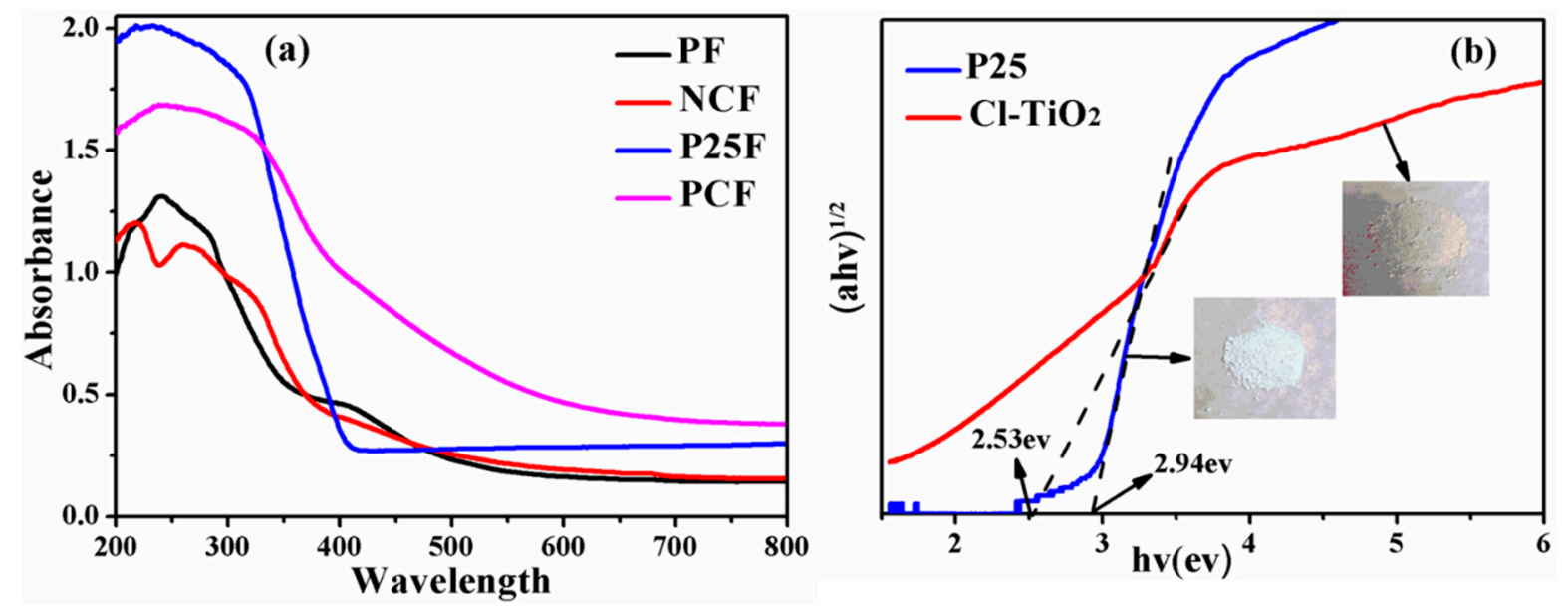

Figure 5. (a) UV-reflection spectra for pure fabric, P25-coated fabric, neoprene-coated fabric, and photocatalyst-coated fabrics. (b) Band baps for $\mathrm{Cl}_{-} \mathrm{TiO}_{2}$ and $\mathrm{P} 25$ based on diffuse reflectance spectra.

X-ray photoelectron spectroscopy was used to characterize the elemental composition and chemical state of $\mathrm{Cl}_{-} \mathrm{TiO}_{2}$. Figure 6a shows a survey scan for $\mathrm{Cl}_{-}-\mathrm{TiO}_{2}$, showing the presence of $\mathrm{Ti}, \mathrm{C}, \mathrm{O}$, and $\mathrm{Cl}$. The $\mathrm{C} 1 \mathrm{~s}$ peak at $284.5 \mathrm{eV}$ can be attributed to carbon incorporated into $\mathrm{TiO}_{2}$ after dechlorination of chloroprene rubber, and to carbon bonded to the chloroprene rubber on the surface of $\mathrm{TiO}_{2}$. Figure $6 \mathrm{~b}$ shows the high-resolution XPS data in the region of the Ti $2 \mathrm{p}$ peaks, located at $464.43 \mathrm{eV}$ and $458.65 \mathrm{eV}$, corresponding to the $\mathrm{Ti}^{4+} 2_{\mathrm{p} 1 / 2}$ and $\mathrm{Ti}^{4+} 2_{\mathrm{p} 3 / 2}$ spin-orbit-split peaks, respectively [7]. As shown in Figure $6 \mathrm{c}$, the $\mathrm{O} 1 \mathrm{~s}$ peak can be fit to three different peaks: the peaks at $529.9 \mathrm{eV}$ and $533.2 \mathrm{eV}$ correspond to the lattice oxygen and surface hydroxyl oxygen of titanium dioxide, respectively [17]; the peak at $531.9 \mathrm{eV}$ can be attributed to oxygen vacancies in $\mathrm{TiO}_{2}$. Figure $6 \mathrm{~d}$ shows the XPS high-resolution spectrum in the $\mathrm{Cl}$ region, which shows three forms of chlorine in the sample. The low-binding-energy peak at $197.9 \mathrm{eV}$, likely corresponds to chlorine adsorbed on the surface of $\mathrm{TiO}_{2}$ [34], either by physical adsorption or chemisorption in place of hydroxyl groups on the surface of $\mathrm{TiO}_{2}$. For F- $\mathrm{TiO}_{2}$, the F $\mathrm{F}^{-}$ adsorbed on the surface can be readily replaced with $\mathrm{OH}^{-}$after washing with concentrated sodium hydroxide, but $\mathrm{F}$ in the $\mathrm{TiO}_{2}$ lattice is not readily replaced [35,36]. We hypothesized that the behavior of $\mathrm{Cl}$ here likely would be similar to that of fluorine, so we washed the $\mathrm{Cl}-\mathrm{TiO}_{2}$ with $1 \mathrm{M} \mathrm{NaOH}$, and characterized the sample using XPS. As shown in Figure 6e, the peak of $197.89 \mathrm{eV}$ was greatly weakened by the washing, but the peaks at $200.09 \mathrm{eV}$ and $201.70 \mathrm{eV}$ were not substantially weakened. These results are consistent with replacement of chloride ions on the $\mathrm{TiO}_{2}$ surface by $\mathrm{OH}^{-}$, and suggest that the peak at $197.9 \mathrm{eV}$ is attributable to chloride ions adsorbed on the surface of $\mathrm{TiO}_{2}$, while the peak at $\approx 200.0 \mathrm{eV} \mathrm{[37]} \mathrm{is} \mathrm{attributable} \mathrm{to} \mathrm{chlorine} \mathrm{doped} \mathrm{into} \mathrm{the} \mathrm{TiO}_{2}$ lattice in place of lattice oxygen. Meanwhile, the peak at $200.70 \mathrm{eV}$ can be attributed to chlorine in the neoprene rubber adhesive on the surface of titanium dioxide; this peak was not affected by $\mathrm{NaOH}$ washing because neoprene is an alkali-resistant material.

Figure 7 compares the EPR spectra for $\mathrm{Cl}-\mathrm{TiO}_{2}$ and P25. P25 exhibits no EPR signal value under vacuum at $100 \mathrm{~K}$, indicating that P25 does not contain solitary electrons of paramagnetic species. An EPR signal can be clearly seen for $\mathrm{Cl}_{-} \mathrm{TiO}_{2}$, corresponding to the capture of a pair of electrons by oxygen vacancies, consistent with the presence of oxygen-vacancy defects in $\mathrm{Cl}_{-} \mathrm{TiO}_{2}$. Again, these results support that chlorine replaces oxygen in the $\mathrm{TiO}_{2}$ lattice, generating oxygen vacancies. 

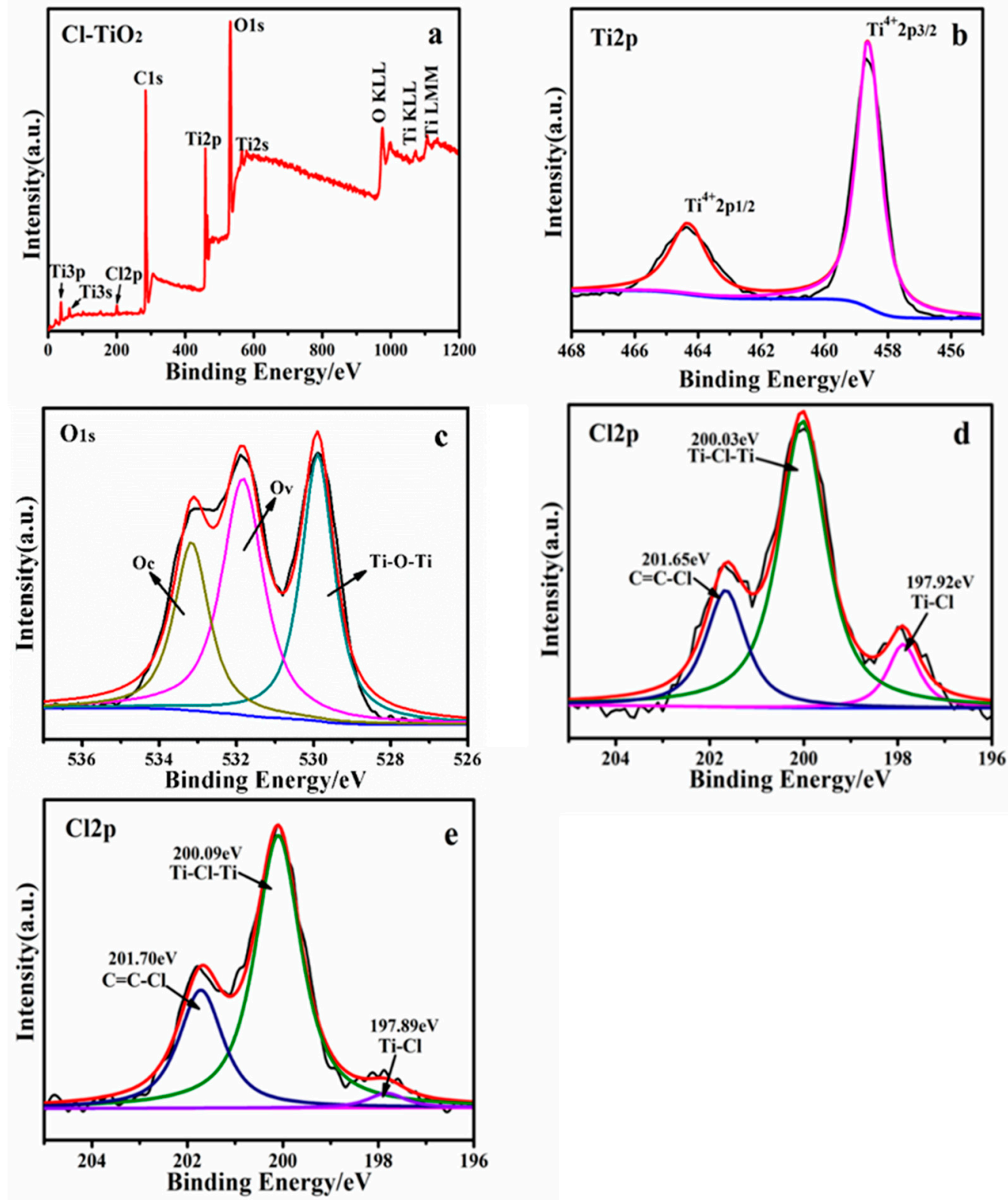

Figure 6. XPS spectra of $\mathrm{Cl}_{-} \mathrm{TiO}_{2}$ : (a) survey spectrum, (b) Ti 2p spectrum, (c) $\mathrm{O} 1$ s spectrum, (d) $\mathrm{Cl} 2 \mathrm{p}$ spectrum, and (e) $\mathrm{Cl} 2 \mathrm{p}$ spectrum after washing with $1 \mathrm{M} \mathrm{NaOH}$.

The efficiency of separation of photogenerated electrons and holes plays an important role in the photocatalytic reaction [38]. Photoluminescence measurements can reveal the photochemical characteristics of semiconductors, and the emission intensity of a PL spectrum represents the efficiency of electron-hole separation in the semiconductor. Figure 8 compares the PL spectrum of $\mathrm{P} 25$ with that for $\mathrm{Cl}-\mathrm{TiO}_{2}$ at an excitation wavelength of $380 \mathrm{~nm}$. The PL emission intensity of $\mathrm{Cl}-\mathrm{TiO}_{2}$ was lower than that of $\mathrm{P} 25$, indicating a lower probability of electron-hole recombination $\mathrm{Cl}-\mathrm{TiO}_{2}$ [39]; therefore, the separation efficiency of electron-hole pairs on the surface of $\mathrm{Cl}_{-}-\mathrm{TiO}_{2}$ during the photocatalytic process might be higher than that of P25 [12]. The lattice oxygen vacancies in $\mathrm{Cl}-\mathrm{TiO}_{2}$ facilitate the capture of photogenerated electrons and promote the separation of electrons and holes [40,41]. The Nyquist diagram (Figure $8 \mathrm{~b}$ ) for P25 exhibited a large radius of curvature, while the plot for $\mathrm{Cl}-\mathrm{TiO}_{2}$ exhibited a small radius of curvature, indicating that doping $\mathrm{TiO}_{2}$ with $\mathrm{Cl}$ causes a large decrease in resistance, which is beneficial to reducing the probability of electron-hole recombination in the composite and improves light utilization. 


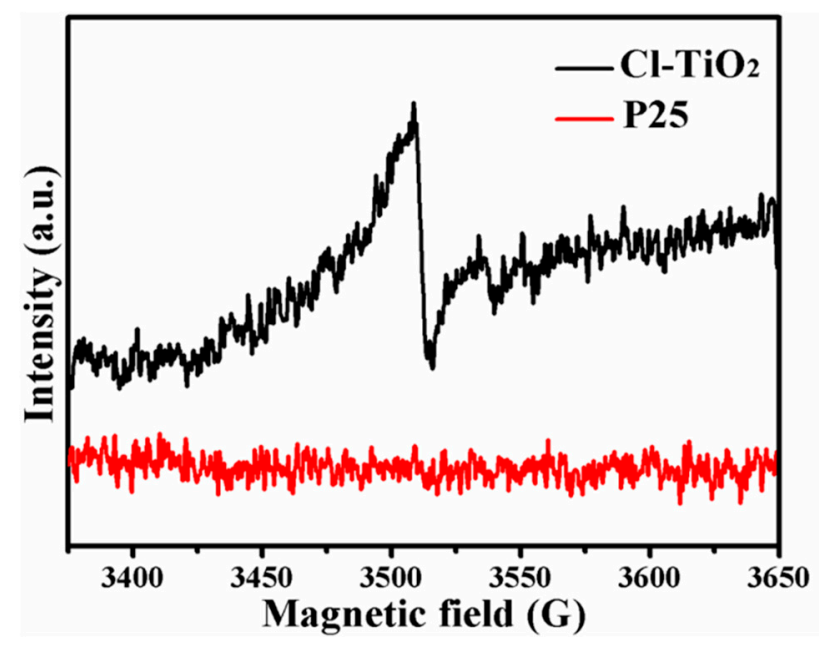

Figure 7. EPR spectra of $\mathrm{P} 25$ and $\mathrm{Cl}-\mathrm{TiO}_{2}$.
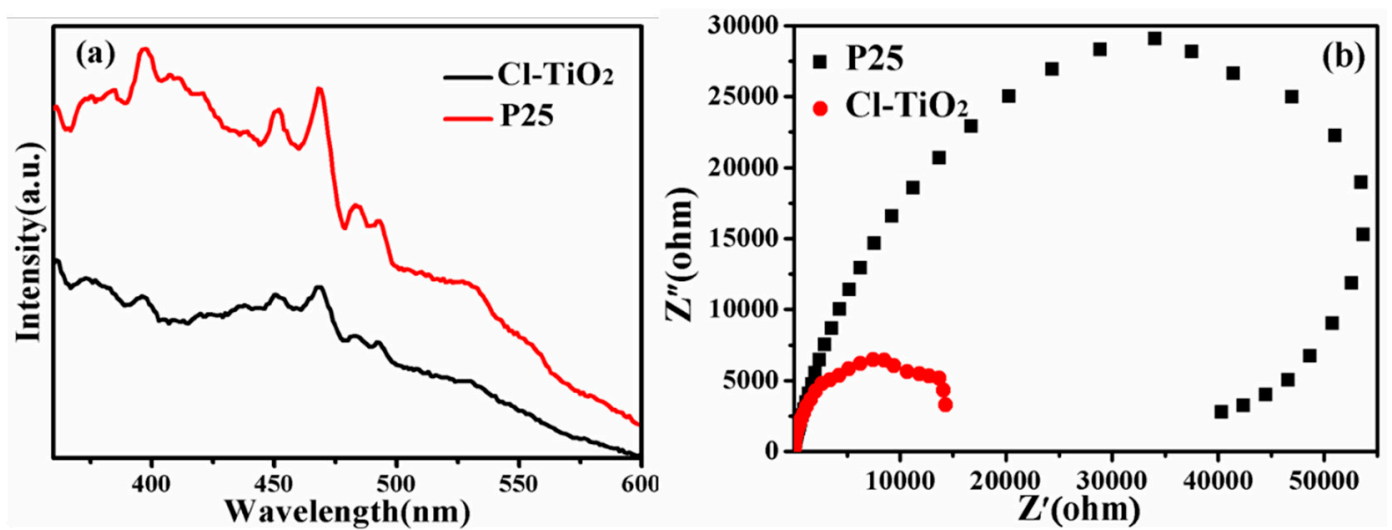

Figure 8. (a) PL spectra, (b) EIS spectra of $\mathrm{P} 25$ and $\mathrm{Cl}-\mathrm{TiO}_{2}$.

Figure 9 shows the photocatalytic activity of photocatalyst-coated fabrics for the degradation of $\mathrm{RhB}, \mathrm{MB}$, and $\mathrm{MO}$ dyes under visible light. The photocatalyst-coated fabric exhibited excellent adsorption for the two cationic dyes; the adsorption mechanism is shown in Scheme 1. The 30-min adsorption-degradation rates reached $66.1 \%$ and $46.0 \%$, respectively (Figure 9d). After $50 \mathrm{~min}$, the photodegradation performances for $\mathrm{RhB}$ and $\mathrm{MB}$ were $95.2 \%$ and 96.0, respectively. As shown in Figure 9a, during the photodegradation of $\mathrm{RhB}$, the solution gradually changed from pink to pale yellow and finally became colorless at $50 \mathrm{~min}$. The maximum absorption peak shifts from $555 \mathrm{~nm}$ to $511 \mathrm{~nm}$, which is caused by RhB de-ethylation [42]. The anionic dye methyl orange was very weakly adsorbed by the composite-coated fabric. However, the photocatalyst-coated fabric also exhibited excellent properties for the degradation of methyl orange under visible light, with the degradation rate reaching 95.4\% after $180 \mathrm{~min}$, far greater than the degradation rate for P25 (Figure 9d). We attribute the increased rate of degradation to $\mathrm{Cl}_{-} \mathrm{TiO}_{2}$ on the surface of the coated fabric being rich in oxygen vacancies, reducing the band gap and enhancing the absorption of visible light. At the same time, the oxygen vacancies are favorable for capturing photogenerated electrons to improve electron-hole separation efficiency and thereby improve photocatalytic efficiency. The holes can oxidize water to generate $\bullet \mathrm{OH}$, and the oxygen vacancies enhance the adsorption of oxygen and promote the generation of $\bullet \mathrm{O}^{2-}$ [43]. Therefore, it is possible that two kinds of free radicals play a major role in the degradation of MO. As shown in Figure 9f, the degradation exhibits characteristics of first-order kinetics. Kinetic constants for photodegradation of $\mathrm{RhB}, \mathrm{MB}$, and $\mathrm{MO}$ dyes by using photocatalyst-coated fabrics are $3.793 \times 10^{-2} \mathrm{~min}^{-1}, 5.191 \times 10^{-2} \mathrm{~min}^{-1}$, and $1.803 \times 10^{-2} \mathrm{~min}^{-1}$, respectively, which are higher than P25-coated fabrics (Figure 9g). In order to eliminate the effect of pure fabric and neoprene 
on the degradation of adsorbed dyes, photocatalytic degradation of $\mathrm{RhB}$ by the pure fabric and neoprene-coated fabric control samples was measured. RhB only very weakly adsorbed to the pure fabric with neoprene. The lifetime of the catalyst plays a key role in the photocatalytic reaction; it is especially important that the photocatalyst strongly adheres to the fabric. We found that the performance of the composite-coated fabric was not reduced after eight cycles of photodegradation of $\mathrm{RhB}$ (Figure 9g), indicating that the photocatalyst-coated fabric has good recycling properties.
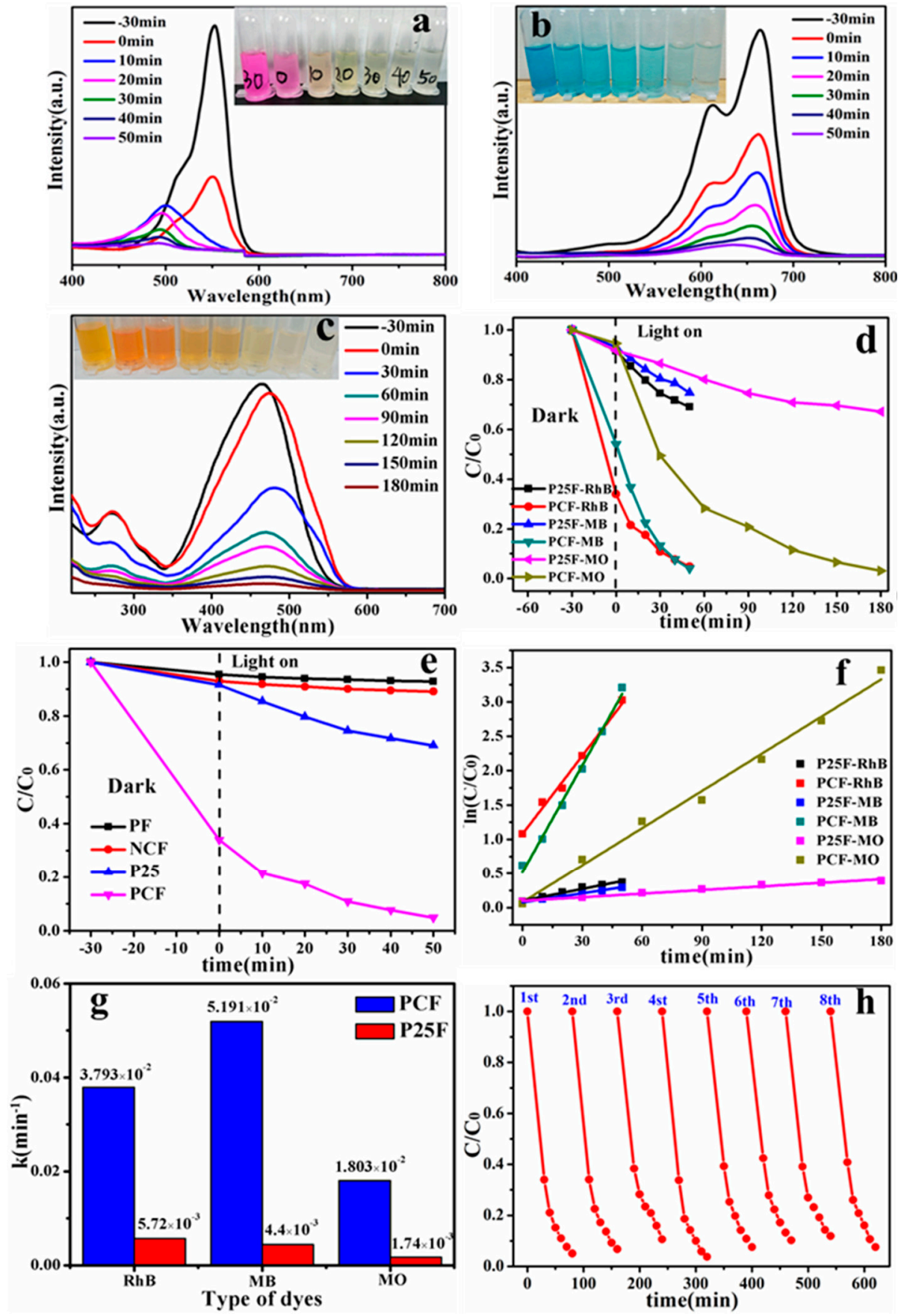

Figure 9. UV-vis absorption spectra over time during the degradation of $\operatorname{RhB}(\mathbf{a}), \mathrm{MB}(\mathbf{b})$, and MO (c) by photocatalyst-coated fabric. (d) Photodegradation of three dyes by photocatalyst-coated fabric. (e) Degradation of RhB by pure fabric, neoprene-coated fabric, P25, and photocatalyst-coated fabric. (f) Pseudo first-order kinetic curve and (g) kinetic constants for photodegradation of three dyes using photocatalyst-coated fabric and P25, (h) recycling of photocatalyst-coated fabric for the photodegradation of RhB. 


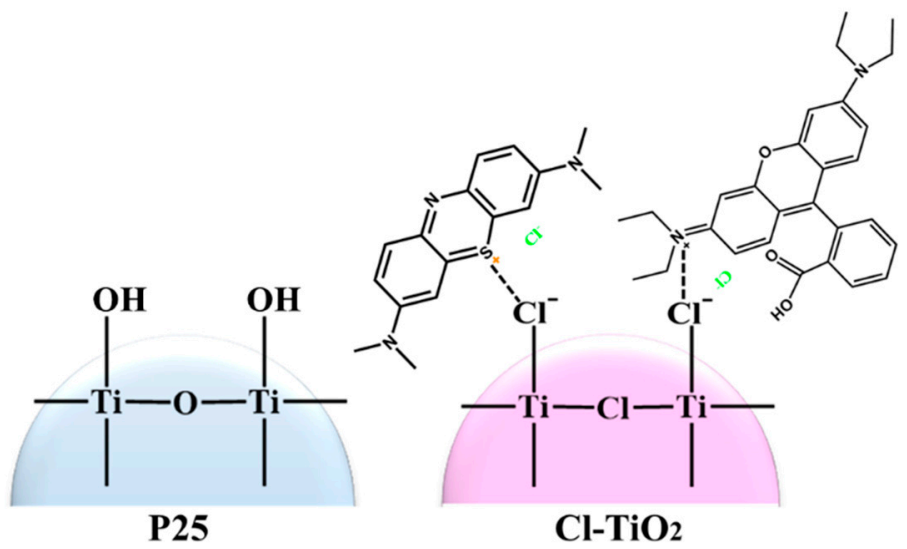

Scheme 1. Adsorption model of cationic dyes on $\mathrm{P} 25$ and $\mathrm{Cl}-\mathrm{TiO}_{2}$.

Active intermediates such as $\mathrm{h}^{+}, \bullet \mathrm{OH}, \bullet \mathrm{O}^{2-}$ are involved in the photocatalytic oxidation of dyes [44-46]. The composite-coated fabric exhibited excellent degradation performance for the cationic dyes because $\mathrm{Cl}-\mathrm{TiO}_{2}$ electrostatically adsorbs cationic dyes, enhancing the photosensitization and promoting dye degradation (Scheme 1). However, the reason for the enhancement of degradation of the anionic dye $\mathrm{MO}$ on the composite-coated fabric remained unclear.

We therefore examined the degradation of $\mathrm{MO}$ by the composite-coated fabric in the presence of ammonium oxalate (AO), benzoquinone (BQ), and isopropanol (IPA) to quench $\mathrm{h}^{+}, \bullet \mathrm{O}^{2-}$, and $\bullet \mathrm{OH}$, respectively. Figure 10b shows the photodegradation rate of $\mathrm{MO}$ was essentially unchanged by the addition of AO. This result is consistent with the inability of $\mathrm{h}^{+}$to oxidize $\mathrm{MO}$, because electrostatic repulsion between $\mathrm{MO}$ and $\mathrm{Cl}-\mathrm{TiO}_{2}$ prevents strong adsorption of dye molecules to the catalyst surface. After the addition of $\mathrm{BQ}$, the efficiency of catalytic degradation of $\mathrm{MO}$ was greatly reduced, with the degradation rate after $180 \mathrm{~min}$ being reduced from $92.2 \%$ to $45 \%$. This result shows that $\bullet \mathrm{O}^{2-}$ plays a major role in photocatalytic degradation of MO. When IPA was added, the efficiency of photocatalytic degradation of $\mathrm{MO}$ also decreased, with the degradation rate over $180 \mathrm{~min}$ being reduced from $92.2 \%$ to $78.6 \%$, showing that $\bullet \mathrm{OH}$ also oxidizes $\mathrm{MO}$, but the catalytic effect is weaker than $\bullet \mathrm{O}^{2-}$. Therefore, we conclude that $\bullet \mathrm{O}^{2-}$ and $\bullet \mathrm{OH}$ free radicals play a key role in the photodegradation of MO. As shown in Figure 10a, the valence band spectrum of $\mathrm{Cl}-\mathrm{TiO}_{2}$ was obtained by XPS spectrum, and the energy level position can be calculated by combining the DRS spectrum. The mechanism of photocatalytic degradation of dyes is shown in Scheme 2. $\mathrm{RhB}$ or $\mathrm{MB}$ was stably adsorbed on the surface of $\mathrm{Cl}-\mathrm{TiO}_{2}$, under visible light excitation, electrons transition from the ground state to the excited state, and then transfer to the conduction band position of $\mathrm{Cl}-\mathrm{TiO}_{2}$, thereby achieving photosensitization of $\mathrm{Cl}_{-} \mathrm{TiO}_{2}$, which underwent self-sensitized degradation. For the $\mathrm{MO}$ system, $\mathrm{Cl}-\mathrm{TiO}_{2}$ was excited by the visible light to produce separation of electron holes, the hole oxidized water to generate $\bullet \mathrm{OH}$, and molecular oxygen was reduced to form $\bullet \mathrm{O}^{2-}$, thereby realizing degradation of $\mathrm{MO}$. 

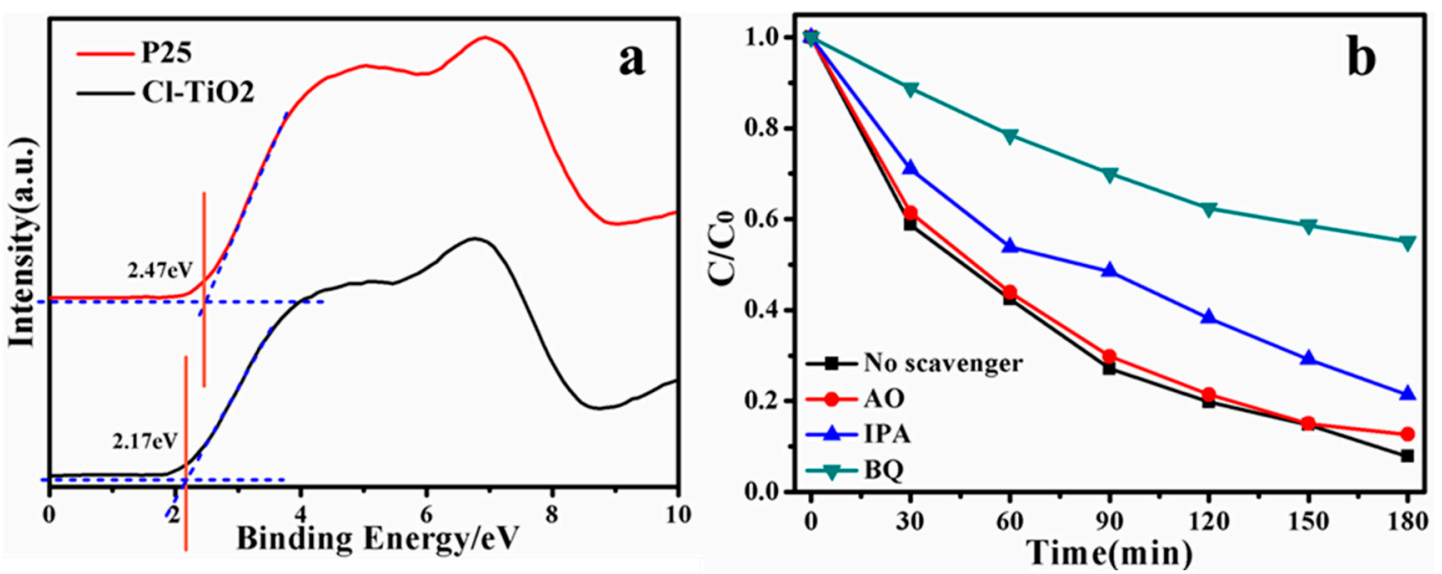

Figure 10. (a) VB XPS spectra of $\mathrm{P} 25$ and $\mathrm{Cl}-\mathrm{TiO}_{2}$. (b) Photodegradation of $\mathrm{MO}$ by composite-coated fabrics in the presence of different capture agents.

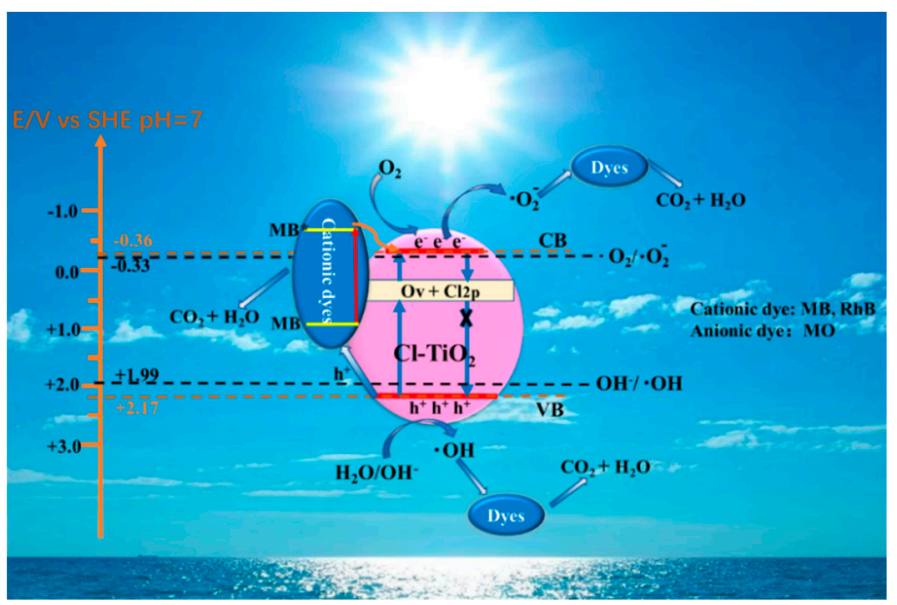

Scheme 2. Degradation pathway of dyes on $\mathrm{Cl}-\mathrm{TiO}_{2}$ photocatalyst.

\section{Materials and Methods}

\subsection{Materials}

Flumes fabric filler was obtained from Hebei Yisheng Environmental Protection Co., Ltd. (Beijing China). Titanium dioxide (P25) was purchased from Degussa. NeopreneSN244X was bought from Shanxi Datong Yujie Chemical Co., Ltd. (Beijing China). Absolute ethanol was supplied by Beijing Chemical Factory (Beijing China). Xylene purchased from Beijing Chemical Factory. Rhodamine B, methyl orange, and methylene blue were acquired from Aladdin Ltd (Beijing China). The chemicals used were of analytical grade and were used as received. The acronyms are as follows: rhodamine $B$ $(\mathrm{RhB})$, methylene blue (MB), methyl orange (MO), photocatalyst-coated fabric (PCF), P25-coated fabric (P25F), fabric-only control samples (PF), neoprene-coated fabric (NCF).

\subsection{Preparation of the $\mathrm{TiO}_{2}$ Suspension and Neoprene Adhesive}

Total of $1.0 \mathrm{~g}$ of $\mathrm{TiO}_{2}$ (P25) was stirred in $100 \mathrm{~mL}$ of absolute ethanol for $2 \mathrm{~h}$, until the $\mathrm{TiO}_{2}$ particles were completely dispersed. A total of $10 \mathrm{~g}$ of neoprene (chloroprene) was cut into small pieces and was stirred in $60 \mathrm{~mL}$ of xylene for $12 \mathrm{~h}$ until the neoprene was completely dissolved.

\subsection{Preparation of Photocatalyst-Coated Fabric}

Flumes fabric $(20 \mathrm{~cm} \times 20 \mathrm{~cm})$ was immersed in a mixture containing $100 \mathrm{~mL}$ ethanol and $100 \mathrm{~mL}$ acetone and was sonicated for $60 \mathrm{~min}$. The fabric was then dried at $60^{\circ} \mathrm{C}$ in an oven. The neoprene 
adhesive was then applied evenly to the surface of the fabric, and the titanium dioxide suspension was sprayed evenly onto both sides of the fabric using a high-pressure spray gun. The coated fabric was dried at $80{ }^{\circ} \mathrm{C}$ for $4 \mathrm{~h}$. After drying, the coated fabric was taken out and placed at room temperature $\left(25^{\circ} \mathrm{C}\right)$ for one week to obtain a photocatalyst-coated fabric (PCF) (Scheme 1). Neoprene-coated fabric (NCF) control samples were made by coating pieces of fabric with only the neoprene adhesive, it was treated by the same drying/ageing procedure. P25-coated fabric (P25F) control samples were made by spraying the fabric with only the P25 dispersion. Fabric-only control samples (PF) were prepared from cleaned pieces of fabric without the neoprene adhesive or P25 particles. The photocatalyst-coated fabric was crushed and dispersed in an ethanol solution, ultrasonicated, washed, and filtered to obtain a Cl- $-\mathrm{TiO}_{2}$ powder. The preparation procedure of photocatalyst-coated fabrics was shown in Scheme 3 . The doping of $\mathrm{Cl}$ in $\mathrm{TiO}_{2}$ was schematically shown in Scheme 4.

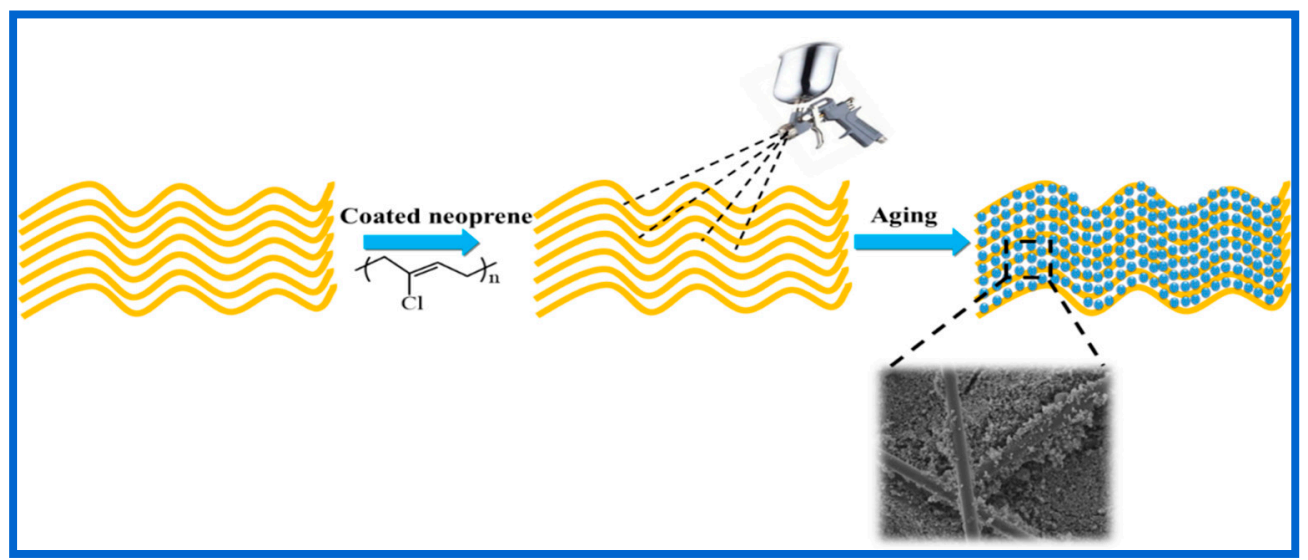

Scheme 3. Preparation procedure of a photocatalyst-coated fabrics.
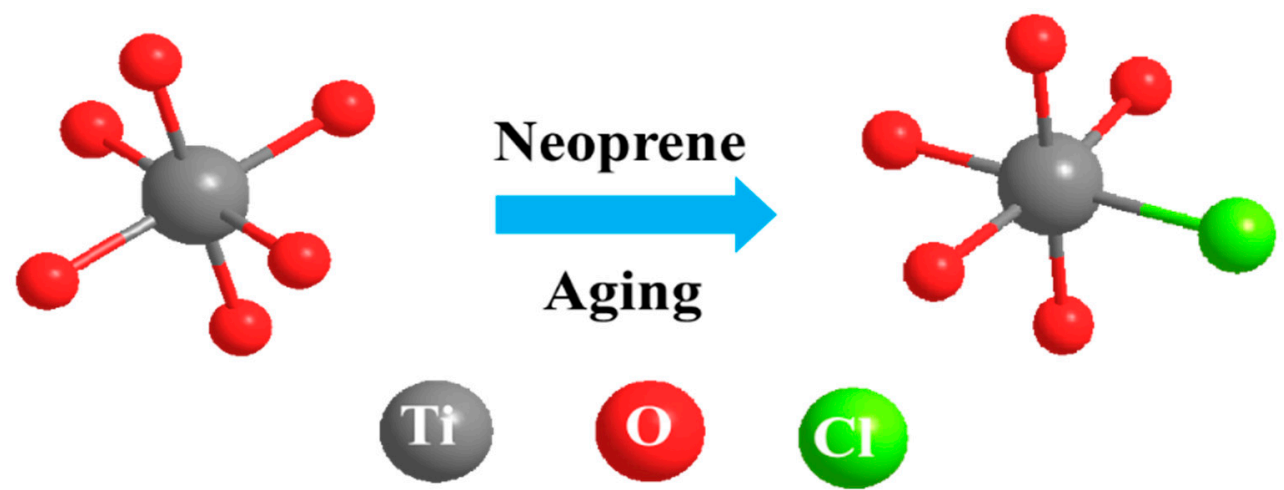

Scheme 4. Evolution of pristine $\mathrm{P} 25$ to $\mathrm{Cl}$-doped $\mathrm{TiO}_{2}$.

\subsection{Characterization}

The dispersion of $\mathrm{TiO}_{2}$ on the surface of catalyst-coated fabrics was characterized using scanning-electron microscopy (Hitachi S-4700, Japan). The morphology of the powdered catalyst was characterized using transmission-electron microscopy (JEOL JEM-2010F, Japan). Lattice parameters and elemental distributions of powdered catalysts were characterized using a transmission-electron microscope (JEOL JEM-3010). X-ray diffractometry was performed using a Shimadzu XRD-6000 (Shimadzu, Japan). The powdered catalyst was also characterized by X-ray photoelectron spectroscopy (XPS, Thermo VG ESCALAB MK II, USA). UV-visible spectroscopy (UV-3600, Shimadzu, Japan) was used to characterize the absorption spectra of the catalyst particles. The fluorescence emission of the powdered catalyst was analyzed using an FL-7000 spectrometer from Tianmei (China) Scientific Instrument Co. Ltd. (Beijing, China), and an excitation wavelength of $360 \mathrm{~nm}$. The zeta potential of the solid powder dispersion was measured by a Shanghai Zhongchen JS94J microelectrophoresis 
apparatus, and the $\mathrm{pH}$ range was 3-11. EPR was carried out using a Bruker A200 spectrometer under normal temperature conditions. The photoelectrochemical properties of solid powdered catalysts were determined using a Shanghai Chenhua $\mathrm{CHI} 660 \mathrm{E}$ electrochemical workstation, a $\mathrm{Ag} / \mathrm{AgCl}$ reference electrode and platinum counter electrode in $0.2 \mathrm{M} \mathrm{Na}_{2} \mathrm{SO}_{4}$ solution.

\subsection{Photocatalytic Experiments}

The chemical structures of the three dyes $\mathrm{RhB}, \mathrm{MB}$ and $\mathrm{MO}$ were shown in Scheme 5 . In order to test the photocatalytic activity of the prepared composite-coated fabrics, the three dyes were irradiated with visible light $(\lambda>425 \mathrm{~nm})$ at an intensity of $100 \mathrm{~mW} / \mathrm{cm}^{2}$. The source of illumination was a $300 \mathrm{~W}$ xenon lamp. The composite-coated fabric $(5 \mathrm{~cm} \times 5 \mathrm{~cm})$ was loaded into a sandwich cell, with liquid water between the interlayers to exclude thermocatalytic degradation. The composite-coated fabric was then placed in contact with a solution containing $100 \mathrm{~mL}$ of rhodamine $\mathrm{B}(\mathrm{RhB})(20 \mathrm{mg} / \mathrm{L})$, methylene blue (MB) $(20 \mathrm{mg} / \mathrm{L})$, or methyl orange (MO) $(20 \mathrm{mg} / \mathrm{L})$, and was left in the dark for $30 \mathrm{~min}$ to allow the sample to reach an adsorption equilibrium with the mixture. The sample was then illuminated from a direction normal to the surface using a light source $10 \mathrm{~cm}$ above the liquid surface. During the photocatalytic reaction, $3 \mathrm{~mL}$ RhB solution or MB solution was extracted from the cell every $10 \mathrm{~min} ; 3$ $\mathrm{mL}$ MO solution was extracted every $30 \mathrm{~min}$. Photocatalytic degradation of RhB by control samples (pure fabric, neoprene-coated fabric, and P25-coated fabric) was measured under the same conditions as for the composite-coated fabrics. The concentration of dye in each extracted aliquot was measured by ultraviolet absorption spectrometry. The rate constant for the degradation of the dye was calculated according to the following formula [42,47]:

$$
\begin{gathered}
\mathrm{DRhB}(\mathrm{DMB}, \mathrm{DMO})=(\mathrm{A} 0-\mathrm{At}) / \mathrm{A} 0 \times 100 \% \\
-\ln (\mathrm{A} 0 / \mathrm{At})=\mathrm{Kt}
\end{gathered}
$$

where $\mathrm{A} 0$ is the initial absorbance of the dye, At is the absorbance of the dye at different time points, $\mathrm{t}$ is the irradiation time, and $\mathrm{K}$ is the rate constant for the photocatalytic reaction.

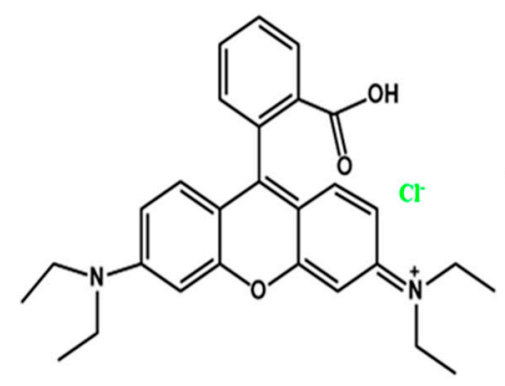

Rhodamine B (RhB)<smiles></smiles><smiles>CN(C)c1ccc(/N=N/c2ccc(S(=O)(=O)O)cc2)cc1</smiles>

Methylene blue (MB)
Methyl orange (MO)

Scheme 5. Chemical structures of the three types of dyes used for photocatalytic degradation.

\section{Conclusions}

We demonstrated a one-step method for producing a photocatalyst-coated fabric for the self-sensitized photodegradation of dyes. In this method, $\mathrm{TiO}_{2}$ particles are bound by a neoprene adhesive to a fabric. The neoprene not only modifies the surface of the $\mathrm{TiO}_{2}$ with $\mathrm{Cl}$ but also dopes the $\mathrm{TiO}_{2}$ lattice with $\mathrm{Cl}$ atoms that replace $\mathrm{O}$ in the lattice, introducing $\mathrm{Ti}^{3+}$ defects into the lattice. $\mathrm{Cl}$ on the surface of the $\mathrm{TiO}_{2}$ particles introduces a negative surface charge to the particles that improves the adsorption of cationic dyes relative to undoped $\mathrm{P} 25 \mathrm{TiO}_{2}$, while $\mathrm{Cl}$ doping in the lattice extends the absorption spectra of the $\mathrm{TiO}_{2}$ particles into the visible region. In combination, these two effects enhance the photocatalytic degradation rates of dyes by composite-coated fabrics relative to degradation rates for P25-coated fabrics. We also showed that the photocatalyst can be recycled while on the surface 
of the fabric. These results suggest that this simple one-step method may prove to be a promising low-cost way for the mass manufacturing of photocatalysts for the treatment of industrial wastewaters.

Author Contributions: X.X. conceived and designed the experiments; Z.C. and T.Z. performed the experiments; X.X., Z.C. and T.Z. analyzed the data; X.X. and Z.C. wrote the manuscript. X.X., T.Z., P.R., D.C., Y.L., L.W. and B.Z. discussed the manuscript. Z.C. and T.Z. contributed equally. All authors have read and agreed to the published version of the manuscript.

Funding: This research was funded by the National Natural Science Foundation of China (Grant 21576016, 21521005), and the Fundamental Research Funds for the Central Universities.

Conflicts of Interest: The authors declare no competing financial interest.

\section{References}

1. Saad, S.A.; Isa, K.M.; Bahari, R. Chemically modified sugarcane bagasse as a potentially low-cost biosorbent for dye removal. Desalination 2010, 264, 123-128. [CrossRef]

2. Aksu, Z. Biosorption of reactive dyes by dried activated sludge: Equilibrium and kinetic modelling. Biochem. Eng. J. 2001, 7, 79-84. [CrossRef]

3. Bhatt, A.S.; Sakaria, P.L.; Vasudevan, M.; Pawar, R.R.; Sudheesh, N.; Bajaj, H.C.; Mody, H.M. Adsorption of an anionic dye from aqueous medium by organoclays: Equilibrium modeling, kinetic and thermodynamic exploration. RSC Adv. 2012, 2, 8663-8671. [CrossRef]

4. Chen, H.; Zhao, J. Adsorption study for removal of Congo red anionic dye using organo-attapulgite. Adsorption 2009, 15, 381-389. [CrossRef]

5. Guptaa, V.K.; Guptaa, B.; Rastogi, A.; Agarwal, S.; Nayaka, A. A comparative investigation on adsorption performances of mesoporous activated carbon prepared from waste rubber tire and activated carbon for a hazardous azo dye-Acid Blue 113. J. Hazard. Mater. 2011, 186, 891-901. [CrossRef]

6. Phugare, S.S.; Kagalkar, A.N.; Govindwar, S.P.; Jadhav, J.P. A study on significant microbial interaction leading to decolorization and degradation of textile dye Rubine 3GP. J. Basic Microbiol. 2011, 51, 499-514. [CrossRef] [PubMed]

7. Linsebigler, A.L.; Lu, G.Q.; Yates, J.T. Photocatalysis on $\mathrm{TiO}_{2}$ Surfaces: Principles, Mechanisms, and Selected Results. Chem. Rev. 1995, 95, 735-758. [CrossRef]

8. Hoffmann, M.R.; Martin, S.T.; Choi, W.Y.; Bahnemann, D.W. Environmental Applications of Semiconductor Photocatalysis. Chem. Rev. 1995, 95, 69-96. [CrossRef]

9. Konishi, J.; Fujita, K.; Nakanishi, K.; Hirao, K. Monolithic $\mathrm{TiO}_{2}$ with Controlled Multiscale Porosity via a Template-Free Sol-Gel Process Accompanied by Phase Separation. Chem. Mater. 2006, 18, 6069-6074. [CrossRef]

10. Fresno, F.; Portela, R.; Suárez, S.; Coronado, J.M. Photocatalytic materials: Recent achievements and near future trends. J. Mater. Chem. A 2014, 2, 2863-2884. [CrossRef]

11. Litter, M.I. Heterogeneous photocatalysis Transition metal ions in photocatalytic systems. Appl. Catal. B Environ. 1999, 23, 89-114. [CrossRef]

12. In, S.L.; Orlov, A.D.; Berg, R.; Garc1, F.; Jimenez, S.P.; Tikhov, M.S.; Wright, D.; Lambert, R.M. Effective Visible Light-Activated B-Doped and B,N-Codoped $\mathrm{TiO}_{2}$ Photocatalysts. J. Am. Chem. Soc. 2007, 129, 13790-13791. [CrossRef] [PubMed]

13. Xing, Z.P.; Li, J.Z.; Wang, Q.; Zhou, W.; Tian, G.H.; Pan, K.; Tian, C.G.; Zou, J.L.; Fu, H.G. A Floating Porous Crystalline $\mathrm{TiO}_{2}$ Ceramic with Enhanced Photocatalytic Performance for Wastewater Decontamination. Eur. J. Inorg. Chem. 2013, 11, 2411-2417. [CrossRef]

14. Liu, N.; Haublein, V.; Zhou, X.M.; Venkatesan, U.; Hartmann, M.; Mackovic, M.; Nakajima, T.; Spiecker, E.; Osvet, A.; Frey, L.; et al. "Black" $\mathrm{TiO}_{2}$ Nanotubes Formed by High-Energy Proton Implantation Show Noble-Metal-co-Catalyst Free Photocatalytic H2-Evolution. Nano Lett. 2015, 15, 6815-6820. [CrossRef] [PubMed]

15. Wang, Y.; Feng, C.X.; Zhang, M.; Yang, J.J.; Zhang, Z.J. Visible light active N-doped $\mathrm{TiO}_{2}$ prepared from different precursors: Origin of the visible light absorption and photoactivity. Appl. Catal. B Environ. 2011, 104, 268-274. [CrossRef] 
16. Ren, W.J.; Ai, Z.H.; Jia, F.L.; Zhang, L.Z.; Fan, X.X.; Zou, Z.G. Low temperature preparation and visible light photocatalytic activity of mesoporous carbon-doped crystalline $\mathrm{TiO}_{2}$. Appl. Catal. B Environ. 2007, 69, 138-144. [CrossRef]

17. Yu, W.; Liu, X.J.; Pan, L.K.; Li, J.L.; Liu, J.Y.; Zhang, J.; Li, C.; Chen, P.; Sun, Z. Enhanced visible light photocatalytic degradation of methylene blue By F-doped $\mathrm{TiO}_{2}$. Appl. Surf. Sci. 2014, 319, 107-112. [CrossRef]

18. Yu, J.C.; Ho, W.K.; Yu, J.G.; Yip, H.Y.; Wong, P.K.; Zhao, J.C. Efficient Visible-Light-Induced Photocatalytic Disinfection on Sulfur-Doped Nanocrystalline Titania. Environ. Sci. Technol. 2005, 394, 1175-1179. [CrossRef]

19. Hong, X.T.; Wang, Z.P.; Cai, W.M.; Lu, F.; Zhang, J.; Yang, Y.Z.; Ma, N.; Liu, Y.J. Visible-Light-Activated Nanoparticle Photocatalyst of Iodine-Doped Titanium Dioxide. Chem. Mater. 2005, 17, 1548-1552. [CrossRef]

20. Chen, X.B.; Liu, L.; Yu, P.Y.; Mao, S.S. Increasing Solar Absorption for Photocatalysis with Black Hydrogenated Titanium Dioxide Nanocrystals. Science 2011, 331, 746-750. [CrossRef]

21. Wang, Z.; Yang, C.Y.; Lin, T.Q.; Yin, H.; Chen, P.; Wan, D.Y.; Xu, F.F.; Huang, F.Q.; Lin, J.H.; Xiand, X.M.; et al. Visible-light photocatalytic, solar thermal and photoelectrochemical properties of aluminium-reduced black titania. Energy Environ. Sci. 2013, 6, 3007-3014. [CrossRef]

22. Zhang, Y.C.; Xing, Z.P.; Zou, J.L.; Li, Z.Z.; Wu, X.Y.; Shen, L.Y.; Zhu, Q.; Yang, S.L.; Zhou, W. 3D urchin-like black $\mathrm{TiO}_{2-\mathrm{x}} /$ carbon nanotube heterostructures as efficient visible-light-driven photocatalysts. RSC Adv. 2017, 7, 453-460. [CrossRef]

23. Lin, T.Q.; Yang, C.Y.; Wang, Z.; Yin, H.; Lu, X.J.; Huang, F.Q.; Lin, J.H.; Xie, X.M.; Jiang, M.H. Effective nonmetal incorporation in black titania with enhanced solar energy utilization. Energy Environ. Sci. 2014, 7, 967-972. [CrossRef]

24. Yan, Y.B.; Miao, J.W.; Yang, Z.H.; Xiao, F.X.; Yang, H.B.; Liu, B.; Yang, Y.H. Carbon nanotube catalysts: Recent advances in synthesis, characterization and applications. Chem. Soc. Rev. 2015, 44, 32-95. [CrossRef] [PubMed]

25. Wang, Q.; Chen, C.C.; Zhao, D.; Ma, W.H.; Zhao, J.C. Change of Adsorption Modes of Dyes on Fluorinated TiO 2 and Its Effect on Photocatalytic Degradation of Dyes under Visible Irradiation. Langmuir 2008, 24, 7338-7345. [CrossRef]

26. Pan, L.; Zou, J.J.; Zhang, X.W.; Wang, L. Water-Mediated Promotion of Dye Sensitization of $\mathrm{TiO}_{2}$ under Visible Light. J. Am. Chem. Soc. 2011, 133, 10000-10002. [CrossRef]

27. Choi, S.S.; Han, D.H. Recovery prediction of thermally aged chloroprene rubber composite using deformation test. J. Appl. Polym. Sci. 2008, 110, 3560-3565. [CrossRef]

28. Kueseng, P.C.; Rattanasom, N.; Deeprasertkul, C. Improvement of the mechanical and thermal properties of silica-filled polychloroprene vulcanizates prepared from latex system. J. Appl. Polym. Sci. 2012, 124, 2657-2668.

29. Berrk, K.; Liu, M.; Chakraborty, K.; Pullan, N.; West, A.; Sammon, C.; Topham, P. Mechanism for cross-linking polychloroprene with ethylene thiourea and zinc oxide. Rubber Chem. Technol. 2014, 88, 80-97. [CrossRef]

30. Wang, Y.Y.; Ding, X.; Chen, X.X.; Chen, Z.; Zheng, K.; Chen, L.; Ding, J.J.; Tian, X.Y.; Zhang, X. Layer-by-layer self-assembly photocatalytic nanocoatingon cotton fabrics as easily recycled photocatalyst for degrading gas and liquid pollutants. Cellulose 2017, 24, 4569-4580. [CrossRef]

31. Kormann, C.; Bahnemann, D.W.; Hoffmann, M.R. Preparation and Characterization of Quantum-Size Titanium Dioxide. J. Phys. Chem. 1988, 92, 5196-5201. [CrossRef]

32. Xu, H.; Zheng, Z.; Zhang, L.Z.; Zhang, H.L.; Deng, F. Hierarchical chlorine-doped rutile $\mathrm{TiO}_{2}$ spherical clusters of nanorods: Large-scale synthesis and high photocatalytic activity. J. Solid State Chem. 2008, 181, 2516-2522. [CrossRef]

33. Wang, X.K.; Wang, C.; Jiang, W.Q.; Guo, W.L.; Wang, J.G. Sonochemical synthesis and characterization of $\mathrm{Cl}$-doped $\mathrm{TiO}_{2}$ and its application in the photodegradation of phthalate ester under visible light irradiation. Chem. Eng. J. 2012, 189-190, 288-294. [CrossRef]

34. Hua, X.; Lizhi, Z. Selective Nonaqueous Synthesis of C-Cl-Codoped $\mathrm{TiO}_{2}$ with Visible-Light Photocatalytic Activity. J. Phys. Chem. C 2010, 114, 11534-11541.

35. Park, H.W.; Choi, W.Y. Effects of $\mathrm{TiO}_{2}$ Surface Fluorination on Photocatalytic Reactions and Photoelectrochemical Behaviors. J. Phys. Chem. B 2004, 108, 4086-4093. [CrossRef]

36. Chen, L.; Yin, S.F.; Huang, R.; Zhang, Q.; Luo, S.L.; Au, C.T. Hollow peanut-like m-BiVO 4 : Facile synthesis and solar-light-induced photocatalytic property. CrystEngComm 2012, 14, 4217-4222. [CrossRef] 
37. Wu, X.; Yin, S.; Dong, Q.; Sato, T. Preparation and visible light induced photocatalytic activity of C-NaTaO 3 and C-NaTaO $3-C l-\mathrm{TiO}_{2}$ composite. Phys. Chem. Chem. Phys. 2013, 15, 20633-20640. [CrossRef]

38. Chen, L.; Zhang, Q.; Huang, R.; Yin, S.F.; Luo, S.L.; Au, C.T. Porous peanut-like $\mathrm{Bi}_{2} \mathrm{O}_{3}-\mathrm{BiVO}_{4}$ composites with heterojunctions: One-step synthesis and their photocatalytic properties. Dalton Trans. 2012, 41, 9513-9518. [CrossRef]

39. Yu, J.C.; Yu, J.G.; Ho, W.K.; Jiang, Z.T.; Zhang, L.Z. Effects of F- Doping on the Photocatalytic Activity and Microstructures of Nanocrystalline $\mathrm{TiO}_{2}$ Powders. Chem. Mater. 2002, 14, 3808-3816. [CrossRef]

40. Choudhury, B.; Dey, M.; Choudhury, A. Shallow and deep trap emission and luminescence quenching of $\mathrm{TiO}_{2}$ nanoparticles on Cu doping. Appl. Nanosci. 2014, 4, 499-506. [CrossRef]

41. Gurylev, V.; Su, C.Y.; Perng, T.P. Surface reconstruction, oxygen vacancy distribution and photocatalytic activity of hydrogenated titanium oxide thin film. J. Catal. 2015, 330, 177-186. [CrossRef]

42. Li, C.M.; Chen, G.; Sun, J.X.; Rao, J.C.; Han, Z.H.; Hu, Y.D.; Xing, W.N.; Zhang, C.M. Doping effect of phosphate in $\mathrm{Bi}_{2} \mathrm{WO}_{6}$ and universal improved photocatalytic activity for removing various pollutants in water. Appl. Catal. B Environ. 2016, 188, 39-47. [CrossRef]

43. Xia, T.; Zhang, Y.L.; Murowchick, J.; Chen, X.B. Vacuum-treated titanium dioxide nanocrystals: Optical properties, Surface disorder, oxygen vacancy, and photocatalytic activities. Catal. Today 2014, 225, 2-9. [CrossRef]

44. Zhou, X.F.; Hu, C.; Hu, X.X.; Peng, T.W.; Qu, J.H. Plasmon-Assisted Degradation of Toxic Pollutants with Ag- $\mathrm{AgBr} / \mathrm{Al}_{2} \mathrm{O}_{3}$ under Visible-Light Irradiation. J. Phys. Chem. C 2010, 114, 2746-2750. [CrossRef]

45. Yang, Y.Q.; Zhang, G.K.; Yu, S.J.; Shen, X. Efficient removal of organic contaminants by a visible light driven photocatalyst $\mathrm{Sr6Bi}_{2} \mathrm{O}_{9}$. Chem. Eng. J. 2010, 162, 171-177. [CrossRef]

46. Li, Y.Y.; Wang, J.S.; Yao, H.C.; Dang, L.Y.; Li, Z.J. Efficient decomposition of organic compounds and reaction mechanism with BiOI photocatalyst under visible light irradiation. J. Mol. Catal. A Chem. 2011, 334, 116-122. [CrossRef]

47. Kaur, A.; Kansal, S.K. $\mathrm{Bi}_{2} \mathrm{WO}_{6}$ nanocuboids: An efficient visible light activephotocatalyst for the degradation of levofloxacin drug in aqueous phase. Chem. Eng. J. 2016, 302, 194-203. [CrossRef]

(C) 2020 by the authors. Licensee MDPI, Basel, Switzerland. This article is an open access article distributed under the terms and conditions of the Creative Commons Attribution (CC BY) license (http://creativecommons.org/licenses/by/4.0/). 